\title{
A novel panel of microRNAs provides a sensitive and specific tool for the diagnosis of breast cancer
}

\author{
JINHUA LUO ${ }^{1,2}$, QING ZHAO $^{2}$, WEI ZHANG ${ }^{3}$, ZHUHONG ZHANG $^{2}$, \\ JING GAO $^{1}$, CHUNYAN ZHANG ${ }^{2}$, YALI LI ${ }^{4}$ and YAPING TIAN ${ }^{1}$

\begin{abstract}
${ }^{1}$ Department of Clinical Biochemistry, Chinese PLA General Hospital, Beijing 100853; ${ }^{2}$ Medical College of Beijing 100853; ${ }^{4}$ Department of Clinical Laboratory, Haidian Hospital, Beijing 100080, P.R. China
\end{abstract} \\ Nankai University, Tianjin 300071; ${ }^{3}$ Department of Gynecology and Obstetrics, Chinese PLA General Hospital,
}

Received April 23, 2013; Accepted March 24, 2014

DOI: $10.3892 / \mathrm{mmr} .2014 .2274$

\begin{abstract}
Breast cancer has a high fatality rate. Early diagnosis reduces the rate of mortality; therefore, novel diagnostic methods are urgently required. The present study investigated the correlation of serum microRNA (miRNA/miR) expression with breast cancer, and tested a panel of miRNAs as promising potential biomarkers for breast cancer. Six miRNAs (miR-374, miR-666-5p, miR-451, miR-148a, miR-27a and miR-30b) were selected for analysis and their differential expression levels were quantified using qPCR. The results demonstrated that four out of the six candidate miRNAs were significantly downregulated in breast cancer patients (miR-451, $\mathrm{P}=0.000$; miR-148a, $\mathrm{P}=0.021$; miR-27a, $\mathrm{P}=0.013$ and miR-30b, $\mathrm{P}=0.001)$. A panel of miRNAs consisting of the four downregulated miRNAs was able to distinguish breast cancer from healthy controls, with an area under the receiver operating characteristic curve of $95.3 \%$, a sensitivity of $94.7 \%$ and a specificity of $82.8 \%$. Thus, this panel of miRNAs may be used as a sensitive and specific tool for the diagnosis of breast cancer.
\end{abstract}

\section{Introduction}

Breast cancer is one of the most common types of cancers among females globally. The disease has a high fatality rate, with $\sim 465,000$ mortalities from breast cancer annually worldwide (1). Early diagnosis reduces the rate of mortality from breast cancer. MicroRNAs (miRNAs/miR) are a class of small non-coding RNAs that were first reported in 1993 (2). miRNAs regulate the post-transcriptional expression of mRNAs (3) and are involved in cell differentiation, survival and apoptosis (4). Due to their significant regulatory role in these processes,

Correspondence to: Dr Yaping Tian, Department of Clinical Biochemistry, Chinese PLA General Hospital, 28 Fu-Xing Road, Beijing 100853, P.R. China

E-mail: tianyp61@gmail.com

Key words: microRNAs, diagnosis, biomarker, breast cancer the misregulation of miRNAs may lead to oncogenesis by increasing cell proliferation, decreasing apoptosis and enhancing the metastatic potential of affected cells (5). In breast cancer, miRNAs have been shown to function as oncogenes and tumor suppressors (6). Several expression profiling studies have identified miRNAs that exhibit upregulated expression patterns in breast tumors. These miRNAs, which are classified as oncogenic, include miR-21, miR-29b, miR-29c, miR-98, miR-122a, miR-128b, miR-136, miR-149, miR-155, miR-181b, miR-181d, miR-191, miR-202, miR-203, miR-210, miR-213, miR-365, miR-373 and miR-520c (7-15). By contrast, let-7a, miR-10b, miR-17-5p, miR-26b, miR-30a-3p, miR-31, miR-34a, miR-101-1, miR-125a, miR-125b, miR-127, miR-143, miR-145, miR-200, miR-204, miR-205, miR-206, miR-320, miR-355, and miR-497 are downregulated in breast cancer (11-18) and are therefore classified as tumor suppressors.

There is a high degree of correlation between serum and tissue miRNA expression profiles (19). Several potential pathways have been hypothesized as the origin of circulating miRNAs in serum: i) Free miRNAs may be directly secreted by cells; ii) miRNAs may be selectively packed into microparticles (MPs) or exosomes and released by cells via shedding of microvesicles (MVs); iii) miRNAs may be enclosed in apoptotic bodies; and iv) miRNAs may also be vesicle-free and associated with either argonaute proteins alone or incorporated into high-density lipoprotein (HDL) particles (20). Recent studies have revealed that secreted miRNA levels in the blood and other body fluids correlate significantly with cancer progression, therapeutic response and patient survival (21). Thus, serum miRNA testing is viewed as a potential non-invasive method for detecting the risk of tumors.

The aim of the present study was to evaluate the feasibility and clinical utility of serum-derived miRNAs as biomarkers for the detection and staging of breast cancer. Six candidate miRNAs (miR-374, miR-666-5p, miR-451, miR-148a, miR-27a and miR-30b) were tested that were selected from 750 breast cancer-associated miRNAs initially identified by pedigree screening conducted in our preliminary experiments. This finding supports the use of miRNAs as biomarkers that may serve as sensitive and specific tools for the diagnosis of breast cancer. 


\section{Materials and methods}

Ethics. All subjects in this study provided written informed consent, and the study was approved by the Committee on Ethics of the Chinese PLA General Hospital (Beijing, China).

Patients and specimen collection. Between August and November 2011, 129 serum samples were obtained from patients at the Chinese PLA General Hospital. These included 29 normal serum samples from healthy volunteers, 20 from benign breast tumor patients and 60 from patients with malignant breast cancer. A total of 20 pairs of pre-operative and post-operative serum samples were collected from patients who had suffered breast cancer and had undergone surgery. Patients were categorized into two groups, stages I/II and stages III/IV, according to the WHO classification of breast cancer (22). Based on this categorization, the present study included 41 samples of breast tumors (stages I-II) and 19 samples of metastatic breast cancer with lymph node metastasis or distant metastasis (stages III-IV). The patient ages were between 20 and 75 years old $(46.81 \pm 12.29$ years old), and a mean body surface area of $166.65 \pm 11.04 \mathrm{~cm}^{2}$ was recorded. Specimens were stored at $-80^{\circ} \mathrm{C}$ until further analysis (Table I).

Statistical analysis. Calculations were performed with the SPSS computer software program (version 19.0 for Windows; SPSS, Inc., Chicago, IL, USA). Results with normal distributions are presented as the mean \pm standard deviation. The mean values of serum miRNA expression from the pre-operative and post-operative groups were compared using paired samples Student's t-test. Results that did not show normal distribution are presented as medians and were compared using the Mann-Whitney U test. Receiver operating characteristic (ROC) curves were generated and the areas under the curve (AUCs) were calculated to compare the predictive value of miRNAs for a breast cancer diagnosis. $\mathrm{P}<0.05$ was considered to indicate a statistically significant difference.

Total RNA isolation from serum samples. All serum samples were immediately collected and stored frozen at $-80^{\circ} \mathrm{C}$ until RNA extraction was conducted. The frozen sera were thawed and transferred into microcentrifuge tubes $(300 \mu 1$ of each serum). Each sample was mixed with $1 \mu$ synthetic cel-miR-67, which served as an internal standard. Isolation of RNA from all samples of malignant and benign tumors and the corresponding healthy controls was performed simultaneously using the miRVana ${ }^{\mathrm{TM}}$ PARIS $^{\mathrm{TM}}$ kit (Ambion, Austin, TX, USA) for serum, according to the manufacturer's instructions. Total RNA, including small RNAs, was purified following extraction, and the RNA concentrations and purities of all samples were measured using the NanoDrop ND8000 Multi-Sample Micro-Volume UV-Vis spectrophotometer (Thermo Fisher Scientific, Wilmington, DE, USA).

Quantitative reverse transcription polymerase chain reaction (qRT-PCR). E. coli polyA polymerase was used to add polyA tails to the premature and mature forms of the miRNAs. Each reaction included $0.5 \mu \mathrm{l}$ E.coli polyA polymerase, $0.5 \mu \mathrm{l}$ 10X RT buffer, $2 \mu 1$ dATPs (Sigma-Aldrich, St. Louis, MO, USA), $0.5 \mu 1 \mathrm{RNasin}{ }^{\circledR}$ ribonuclease inhibitor (Takara) and
Table I. Clinicopathological features of breast cancer patients.

\begin{tabular}{lcc}
\hline Variable & $\begin{array}{c}\text { Clinicopathological } \\
\text { parameter }\end{array}$ & $\begin{array}{c}\text { Samples } \\
(\mathrm{n}=129)\end{array}$ \\
\hline Age & $46.81 \pm 12.29$ & \\
Body surface area, $\mathrm{cm}^{2}$ & $166.65 \pm 11.04$ & 80 \\
Breast cancer & 60 \\
Pre-operative & 20 \\
Post-operative & 20 \\
Benign tumor & 29 \\
Normal control & 41 \\
TNM stage & 19 \\
I-II & \\
III-IV & \\
\hline A total of 41 samples were from pathological stages $\leq$ II (i.e. early) \\
and 19 from pathological stages $\geq$ III (i.e. late). TNM, tumor node \\
metastasis.
\end{tabular}

Table II. List of all primers used in PCR.

\begin{tabular}{ll}
\hline Primer & \multicolumn{1}{c}{ Sequence $\left(5^{\prime}-3^{\prime}\right)$} \\
\hline miR-374 & S: ATAATACAACCTGCTA \\
A: CTCACACGACTCACGA & S: GCGGGCACAGCT \\
A: CTCACACGACTCACGA & S: ACCGTTACCATTACT \\
miR-451 & A: CTCACACGACTCACGA \\
miR-148a & S: GGGTCAGTGCACT \\
miR-27a & A: CTCACACGACTCACGA \\
& S: TCACAGTGGCTAAGT \\
miR-30b & A: CTCACACGACTCACGA \\
& S: GTAAACATCCTACAC \\
Cel-miR-67 & A: CTCACACGACTCACGA \\
& S: CAACCTCCTAGA \\
& A: CTCACACGACTCACGA
\end{tabular}

miR, microRNA; PCR, polymerase chain reaction; $\mathrm{S}$, sense; A, antisense.

$10 \mathrm{pg}$ total RNA. The reaction was incubated at $37^{\circ} \mathrm{C}$ for $1 \mathrm{~h}$. Next, $1 \mu \mathrm{l} 0.5 \mu \mathrm{g} / \mu \mathrm{l}$ RT primer was added and the reaction was incubated at $70^{\circ} \mathrm{C}$ for $5 \mathrm{~min}$, then placed on ice immediately for at least $2 \mathrm{~min}$ to disrupt the secondary structures formed between the RNA and the primer. Aliquots of $20 \mu \mathrm{l}$ from the reverse transcriptase reactions contained $0.5 \mu 15 \mathrm{U} / \mu 1 \mathrm{M}-\mathrm{MLV}$ reverse transcriptase, $4 \mu \mathrm{l}$ buffer, $1 \mu 1 \mathrm{dNTP}(10 \mathrm{mM}), 10 \mu \mathrm{l}$ A-plus reaction mix, $0.5 \mu 1 \mathrm{RNasin}$ ribonuclease inhibitor and $4 \mu \mathrm{l}$ RNase-free water. These reverse transcription reactions were incubated at $42^{\circ} \mathrm{C}$ for $1 \mathrm{~h}$. Finally, for amplification of the cDNA targets, the following 20- $\mu 1$ reactions were assembled: $1 \mu \mathrm{l}$ cDNA, $2 \mu \mathrm{l}$ of 10X universal primer, $2 \mu \mathrm{l}$ of 10X gene-specific primer (10 $\mu \mathrm{M}$; Table II), $10 \mu \mathrm{l}$ of $2 \mathrm{X}$ qPCR 
A

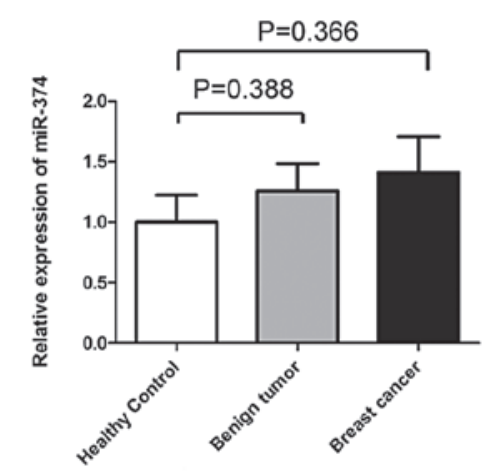

D

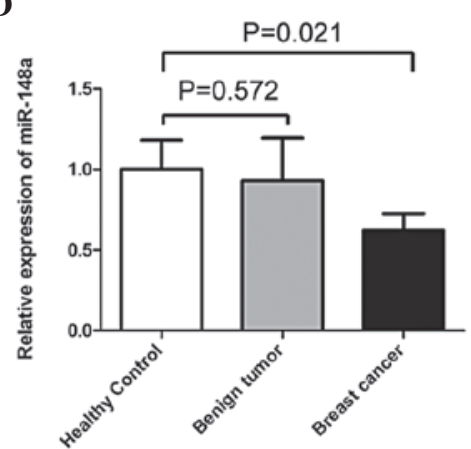

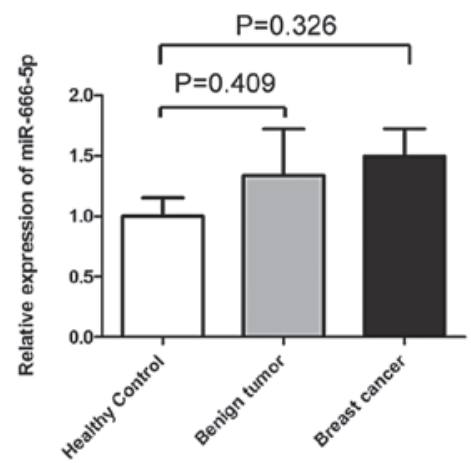

$\mathbf{E}$

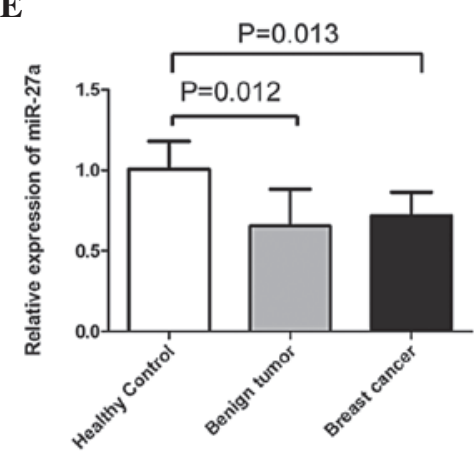

C

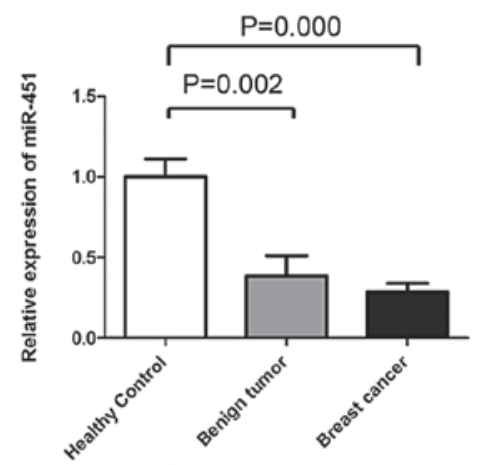

F

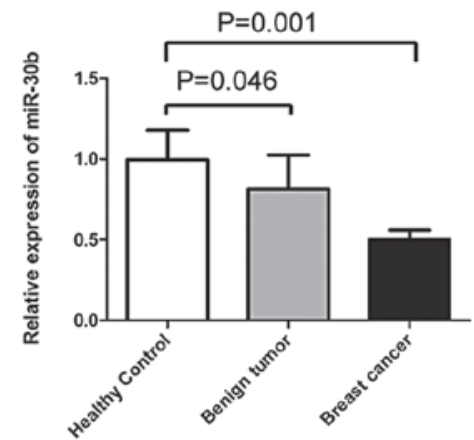

Figure 1. Expression levels of (A) miR-374, (B) miR-666-5p, (C) miR-451, (D) miR-148a, (E) miR-27a and (F) miR-30b. Comparison among healthy controls, benign breast tumor and breast cancer patients.

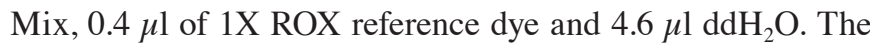
reactions were heated to $95^{\circ} \mathrm{C}$ for $5 \mathrm{~min}$, followed by 40 cycles of $95^{\circ} \mathrm{C}$ for $15 \mathrm{sec}$ and $60^{\circ} \mathrm{C}$ for $1 \mathrm{~min}$. Cel-miR-356 was used as an internal standard control for normalization in the qPCR analysis. Gene expression levels were quantified using the ABI 7900 detection system (Applied Biosystems, Foster City, CA, USA). All RT reactions included no-template (no cDNA) and negative (no reverse transcriptase) controls, and were performed in triplicate. $\mathrm{Ct}$ (threshold cycle for a sample) data were used to evaluate the precision and reproducibility of the qPCR results. The expression levels of miRNAs were calculated using $2^{-\Delta \Delta \mathrm{Ct}}$, where $\Delta \mathrm{Ct}=(\mathrm{Ct}$ miRNA $-\mathrm{Ct}$ cel-miR-67). $\Delta \Delta \mathrm{Ct}$ was calculated using the formula: $\Delta \Delta \mathrm{Ct}=\Delta \mathrm{Ct}$ of the disease group - $\Delta \mathrm{Ct}$ of the control group. All reagents/mixes were provided by Quantobio (Beijing, China).

\section{Results}

Serum miRNA expression levels. Six target miRNAs (miR-374, miR-666-5p, miR-451, miR-148a, miR-27a and miR-30b) were selected for further analysis in serum samples. As shown in Fig. 1, four out of the six candidate miRNAs tended to be differentially expressed in serum samples between the patients with breast cancer and the healthy controls: miR-374, $\mathrm{P}=0.366$; miR-666-5p, $\mathrm{P}=0.326$; miR-451, $\mathrm{P}=0.000$; miR-148a, $\mathrm{P}=0.021$; miR-27a, $\mathrm{P}=0.013$; and miR-30b, $\mathrm{P}=0.001$. Three out of the six miRNAs (miR-451, miR-27a and miR-30b) showed significantly different expression levels between the benign breast tumor groups and the healthy controls: miR-374, $\mathrm{P}=0.388$; miR-666-5p, $\mathrm{P}=0.409$; miR-451, $\mathrm{P}=0.002 ; \mathrm{miR}-148 \mathrm{a}, \mathrm{P}=0.572$; miR-27a, $\mathrm{P}=0.012$; and $\mathrm{miR}-30 \mathrm{~b} \mathrm{P}=0.046$.
No significant differences were observed in the expression levels of miR-374, miR-666-5p, miR-451, miR-148a, miR-27a or miR-30b between the malignant and benign breast tumors (miR-374, $\mathrm{P}=0.870$; miR-666-5p, $\mathrm{P}=0.100$; miR-451, $\mathrm{P}=0.839$; miR-148a, $\mathrm{P}=0.121 ; \mathrm{miR}-27 \mathrm{a}, \mathrm{P}=0.875$; and miR-30b, $\mathrm{P}=0.511)$.

Paired sample t-tests were performed to compare miRNA expression in the serum samples prior to treatment and three days after the surgery from 20 breast cancer patients who underwent surgery. miRNA expression was not significantly different between the pre- and post-operative groups (miR-374, $\mathrm{P}=0.514$; miR-666-5p, $\mathrm{P}=0.873$; miR-451, $\mathrm{P}=0.154$; miR-148a, $\mathrm{P}=0.740$; miR-27a, $\mathrm{P}=0.588$; and miR-30b, $\mathrm{P}=0.091$ ).

Comparisons of the predictive values of miRNAs. A ROC curve analysis was used to compare the predictive diagnostic values of the miRNAs studied for the breast cancer, benign breast tumor and healthy control groups. These results, presented in Table III, showed that miR-451 had the highest AUC of 0.915 [asymptotic 95\% confidence interval (CI), 0.850-0.979; $\mathrm{P}<0.000]$. miR-27a is inferior to miR-451 and showed an AUC of 0.909 (asymptotic 95\% CI, 0.841-0.976; $\mathrm{P}<0.000$ ). miR-451 had a sensitivity of $93 \%$ and a specificity of $79.3 \%$, while miR-27a had a sensitivity of $88.1 \%$ and a specificity of $86.2 \%$.

The results shown in Table IV demonstrated that miR-451 also had the highest AUC for differentiating between the benign breast tumor cases and healthy controls, with a sensitivity of $100 \%$ and a specificity of $69 \%$. Thus, miR-451 is a highly accurate predictor for the initial screening of breast diseases. 
Table III. Parameters for predictive value of panel 1.

\begin{tabular}{|c|c|c|c|c|c|}
\hline miRNA & AUC & CI & Sensitivity & Specificity & P-value \\
\hline $\operatorname{miR}-451^{\mathrm{a}}$ & 0.915 & $0.850-0.979$ & 0.930 & 0.793 & 0.000 \\
\hline $\operatorname{miR}-148 \mathrm{a}^{\mathrm{a}}$ & 0.889 & $0.821-0.957$ & 0.763 & 0.966 & 0.000 \\
\hline $\operatorname{miR}-27 a^{a}$ & 0.909 & $0.841-0.976$ & 0.881 & 0.862 & 0.000 \\
\hline $\operatorname{miR}-30 b^{a}$ & 0.900 & $0.829-0.971$ & 0.881 & 0.828 & 0.000 \\
\hline Panel 1 & 0.953 & $0.915-0.992$ & 0.947 & 0.828 & 0.000 \\
\hline
\end{tabular}

${ }^{a}$ Items included in panel 1; $\mathrm{P}<0.05$. miRNA, microRNA; CI, confidence interval; AUC, area under the curve.

Table IV. Parameters for predictive value of panel 2.

\begin{tabular}{|c|c|c|c|c|c|}
\hline miRNA & AUC & CI & Sensitivity & Specificity & $\mathrm{P}$-value \\
\hline $\operatorname{miR}-451^{\mathrm{a}}$ & 0.904 & $0.823-0.985$ & 1 & 0.690 & 0.000 \\
\hline $\operatorname{miR}-27 \mathrm{a}^{\mathrm{a}}$ & 0.791 & $0.635-0.948$ & 0.400 & 0.966 & 0.001 \\
\hline $\operatorname{miR}-30 b^{a}$ & 0.706 & $0.552-0.860$ & 0.800 & 0.862 & 0.017 \\
\hline Panel 2 & 0.880 & $0.891-0.983$ & 0.850 & 0.862 & 0.000 \\
\hline
\end{tabular}

atems included in panel 2; $\mathrm{P}<0.05$. miRNA, microRNA; CI, confidence interval; AUC, area under the curve.
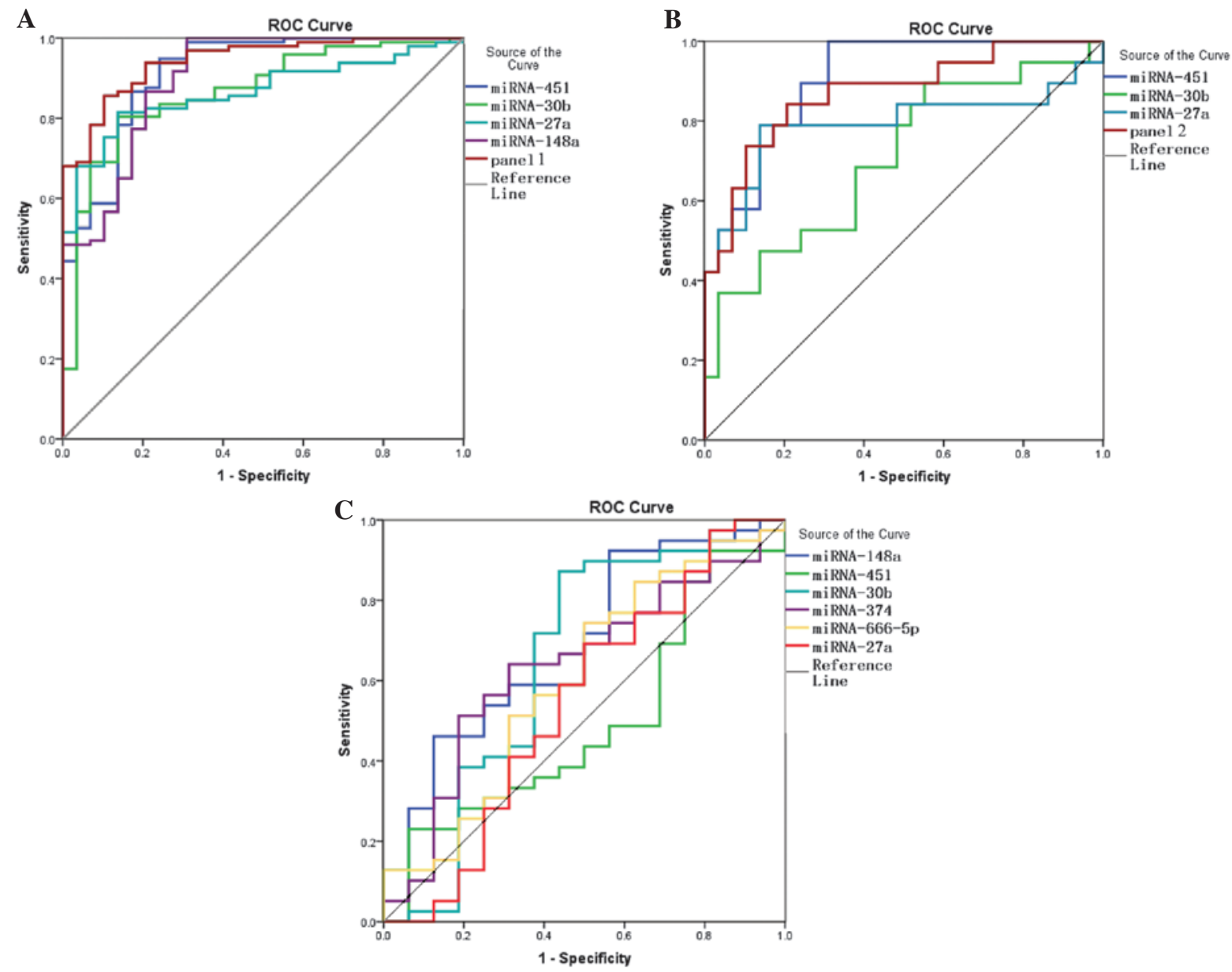

Figure 2. ROC curve analysis with multiple markers compared with a single marker. (A) ROC curves for the individual miRNAs and panel 1 for the diagnosis between breast cancer and healthy control groups. (B) ROC curves for the individual miRNAs and panel 2 for the diagnosis between benign breast tumor and healthy control groups. (C) ROC curves for the individual miRNAs for the diagnosis between the benign and malignant breast tumor groups. miRNA, microRNA; ROC, receiver operating characteristic. 
These results also show that miR-148a levels differentiated between malignant and benign breast masses, with an AUC of $69.8 \%$ (asymptotic 95\% CI, 0.561-0.835), a sensitivity of $56.1 \%$ and a specificity of $78.9 \%$.

Multiple marker assays. Multiple marker assays evaluated by multivariate regression analysis may significantly improve the sensitivity and specificity of detecting tumors compared with single marker assays.

The combined panel of miRNA markers (panel 1; miR-451, miR-148a, miR-27a and miR-30b) achieved $94.7 \%$ sensitivity, $82.8 \%$ specificity and a $95.3 \%$ AUC for distinguishing breast cancer cases from healthy controls (Table III; Fig. 2A).

A panel of three combined markers (panel 2; miR-451, miR-27a and miR-30b) achieved $85 \%$ sensitivity, $86.2 \%$ specificity and attained an $88 \%$ AUC for distinguishing benign breast tumor cases from healthy controls (Table IV; Fig. 2B).

The single marker miR-148a showed a potential predictive value in differentiating between malignant and benign breast masses $(\mathrm{P}=0.01)$, with a sensitivity of $56.1 \%$, a specificity of $78.9 \%$ and an AUC of $69.8 \%$ (Fig. 2C).

\section{Discussion}

The present study was designed to investigate the expression and correlation of a selected panel of miRNAs associated with breast tumors in serum samples. Indeed, miRNAs are known to be involved in several critical oncogenic cellular processes, including proliferation, differentiation and apoptosis. Serum-derived miRNAs have the following characteristics: i) miRNAs are tremendously stable in serum due to their small size (23); ii) circulating miRNAs may be easily and reproducibly measured (24); and iii) miRNAs have rich information content and tumor-specific profiles (25), and individual miRNAs show unique expression levels in the varying organs and stages of cellular processes. In addition, clinical specimens of serum are more abundant and more conveniently collected. Therefore, serum-derived miRNAs are expected to be clinically useful as novel and minimally invasive tools to aid in the early detection and monitoring of breast cancer.

Six miRNAs from the expression profile (miR-374, miR-666-5p, miR-451, miR-148a, miR-27a and miR-30b) were empirically selected for the qPCR analysis of serum samples collected from breast cancer patients, benign tumor patients and healthy controls. The aberrant expression of candidate miRNAs in breast cancer has been reported by several previous studies. For example, it has been demonstrated that miR-451 levels are significantly reduced in tamoxifen-resistant breast cancer cells (26). In MCF-7/DOX cells, the enforced increase of miR-451 levels downregulates the expression levels of mdr1 and increases the sensitivity of the MCF-7-resistant cancer cells to DOX (27). However, miR-451 shows higher expression levels in breast invasive micropapillary carcinoma than in unspecified invasive ductal carcinomas (28). The expression levels of miR-148a are decreased in breast cancer cells and tissues (29). miR-27a appears to be significant in breast cancer by suppressing the expression of a transcription factor, ZBTB10 (30). Furthermore, the single nucleotide polymorphism in miR-27a has been associated with the risk of familial breast cancer and has also been correlated with lymph node metas- tasis (31). miR-30b, a member of the miR-30 family, is a tumor suppressor miRNA that binds to the 3'-UTR of the catalase mRNA and inhibits its expression (32). In addition, miR-30b has been identified as a trastuzumab-inducible miRNA in cancer cells (33), and expression levels of miR-30b have been shown to correctly predict the nature of inflammatory breast cancer phenotypes (34). To the best of our knowledge, there are few studies on the expression of miR-666-5p and miR-374 in breast cancer. miR-374, together with four other miRNAs (miR-21, miR-31, miR-125a and miR-181c), has been described as a signature marker of the human natural T-reg cell (35), and it is abundantly expressed in transdifferentiated neuronal progenitors (36). Furthermore, the majority of the studies previously undertaken have focused on comparing miRNA expression patterns in breast tumor tissues or in cancer cell lines. Thus, to a certain extent, the present research involving the testing of serum miRNA expression profiling and its use as a diagnostic tool is a pioneering approach.

The present results show that miR-451, miR-27a and miR-30b are differentially expressed in the serum samples in benign and malignant breast tumors compared with the samples of healthy patients. Therefore, these miRNAs may be used to discriminate breast cancer from healthy controls. In addition, miR-148a may be used to distinguish benign breast tumors from malignant tumors due to its differential serum levels in these two groups. The results of the present study confirm that miR-451 expression provides the greatest sensitivity in detecting human breast cancers, which is consistent with data that has been previously reported (37).

Certain studies have indicated that the removal of the primary tumor leads to the loss of elevated levels of circulating miRNAs $(38,39)$. In the present study, no significant differences were observed in the expression levels of miR-374, miR-666-5p, miR-451, miR-148a, miR-27a and miR-30b between the pre-operative and post-operative serum samples of the breast cancer patients. However, as the study had a relatively small sample size of only 20 paired patients, a greater number of breast cancer patients should be investigated to confirm these results. In addition, the post-operative serum samples used in this study were collected only three days after surgery. Thus, the levels of circulating miRNAs at various periods subsequent to surgery should be investigated.

Furthermore, the present study also attempted to evaluate the expression levels of the panel of miRNAs at differing tumor stages. Certain previous studies have shown that differential miRNA expression in serum is more frequently observed in the advanced, rather than early, stages of breast cancer (40). Therefore, the expression levels of miRNAs have been linked to the tumor stage. In the present study, miRNA expression profiling was not demonstrated to show a higher sensitivity for patients with a higher tumor-node-metastasis stage and lymph node metastasis.

The present study of miRNAs with downregulated expression in disease patient samples demonstrated that the serum levels of cancer-associated miRNAs can distinguish patients with breast cancer from healthy controls. However, miR-27a is regarded as a risk factor for colorectal cancer (41) and has also shown to be correlated with lymph node metastasis in gastric cancer (42). Furthermore, miR-451 levels are decreased in serum samples from renal cell carcinoma patients (43), and 
miR-148a expression is suppressed $>4$-fold in gastric cancer. The role of miR-148a is to function as a tumor metastasis suppressor in gastric cancer, hence, downregulation of miR-148a contributes to gastric cancer lymph node metastasis and progression (44). Finally, the expression of miR-30b is suppressed in invasive bladder cancer (45) and lung squamous cell carcinoma (46).

Therefore, the specificity of a single miRNA as a tumor marker is somewhat less than that of multiple miRNAs together. Multiple marker assays may significantly improve the sensitivity and specificity of tumor detection compared with single marker assays. However, this improvement in detection is dependent upon the selection of markers. In the present study, miR-451, miR-148a, miR-27a and miR-30b were combined into a panel of markers for breast cancer diagnosis. The sensitivities of miR-451, miR-148a, miR-27a and miR-30b individually were $93,76.3,88.1$ and $88.1 \%$, respectively. In addition, their specificities were 79.3, 96.6, 86.2 and $82.8 \%$, respectively. By comparison, the sensitivity and specificity of the four combined markers were significantly higher. The ROC curve analysis using the four combined markers yielded an AUC of 0.953 , a sensitivity of $94.7 \%$ and a specificity of $82.8 \%$.

In conclusion, qPCR analysis of miRNAs in the serum samples of breast cancer patients may have a clinical significance for the detection of breast cancer. Moreover, the present results indicate that a panel of miRNAs may be useful as a sensitive and specific tool for the detection of breast cancer. However, studies with long-term follow-up and a larger number of patients are required in order to confirm the clinical application of these molecular markers.

\section{References}

1. Jemal A, Siegel R, Ward E, Hao Y, Xu J and Thun MJ: Cancer statistics, 2009. CA Cancer J Clin 59: 225-249, 2009.

2. Lee RC, Feinbaum RL and Ambros V: The C. elegans heterochronic gene lin-4 encodes small RNAs with antisense complimentary to lin-14. Cell 75: 843-854, 1993.

3. Kim VN, Han J and Siomi MC: Biogenesis of small RNAs in animals. Nat Rev Mol Cell Biol 10: 126-139, 2009.

4. Wang ZX, Lu BB, Wang H, Cheng ZX and Yin YM: MicroRNA-21 modulates chemosensitivity of breast cancer cells to doxorubicin by targeting PTEN. Arch Med Res 42: 281-290, 2011.

5. Di Leva G and Croce CM: Roles of small RNAs in tumor formation. Trends Mol Med 16: 257-267, 2010.

6. Chen CZ: MicroRNAs as oncogenes and tumor suppressors. N Engl J Med 353: 1768-1771, 2005.

7. Selcuklu SD, Donoghue MT and Spillane C: miR-21 as a key regulator of oncogenic processes. Biochem Soc Trans 37: 918-925, 2009.

8. Faraoni I, Antonetti FR, Cardone J and Bonmassar E: miR-155 gene: a typical multifunctional microRNA. Biochim Biophys Acta 1792: 497-505, 2009.

9. Wang Y and Lee CG: MicroRNA and cancer - focus on apoptosis. J Cell Mol Med 13: 12-23, 2009.

10. Yan LX, Huang XF, Shao Q, Huang MY, Deng L, Wu QL, Zeng YX and Shao JY: MicroRNA miR-21 overexpression in human breast cancer is associated with advanced clinical stage, lymph node metastasis and patient poor prognosis. RNA 14: 2348-2360, 2008.

11. Iorio MV, Ferracin M, Liu CG, Veronese A, Spizzo R, Sabbioni S, Magri E, Pedriali M, Fabbri M, Campiglio M, et al: MicroRNA gene expression deregulation in human breast cancer. Cancer Res 65: 7065-7070, 2005.

12. Lodygin D, Tarasov V, Epanchintsev A, Berking C, Knyazeva T, Körner H, Knyazev P, Diebold J and Hermeking H: Inactivation of miR-34a by aberrant CpG methylation in multiple types of cancer. Cell Cycle 7: 2591-2600, 2008.
13. Sempere LF, Christensen M, Silahtaroglu A, Bak M, Heath CV, Schwartz G, Wells W, Kauppinen S and Cole CN: Altered MicroRNA expression confined to specific epithelial cell subpopulations in breast cancer. Cancer Res 67: 1161211620,2007

14. Kondo N, Toyama T, Sugiura H, Fujii Y and Yamashita H: miR-206 expression is down-regulated in estrogen receptor alpha -positive human breast cancer. Cancer Res 68: 50045008, 2008.

15. Huang Q, Gumireddy K, Schrier M, le Sage C, Nagel R, Nair S, Egan DA, Li A, Huang G, Klein-Szanto AJ, et al: The microRNAs miR-373 and miR-520c promote tumour invasion and metastasis. Nat Cell Biol 10: 202-210, 2008.

16. Valastyan S, Reinhardt F, Benaich N, Calogrias D, Szász AM, Wang ZC, Brock JE, Richardson AL and Weinberg RA: A pleiotropically acting microRNA, miR-31, inhibits breast cancer metastasis. Cell 137: 1032-1046, 2009.

17. Volinia S, Calin GA, Liu CG, Ambs S, Cimmino A, Petrocca F, Visone R, Iorio M, Roldo C, Ferracin M, et al: A microRNA expression signature of human solid tumors defines cancer gene targets. Proc Natl Acad Sci USA 103: 2257-2261, 2006.

18. Liu XX, Li XJ, Zhang B, Liang YJ, Zhou CX, Cao DX, He M, Chen GQ, He JR and Zhao Q: MicroRNA-26b is underexpressed in human breast cancer and induces cell apoptosis by targeting SLC7A11. FEBS Lett 585: 1363-1367, 2011.

19. Wang F, Zheng Z, Guo J and Ding X: Correlation and quantitation of microRNA aberrant expression in tissues and serum from patients with breast tumor. Gynecol Oncol 119: 586-593, 2010.

20. Turchinovich A, Weiz L and Burwinkel B: Extracellular miRNAs: the mystery of their origin and function. Trends Biochem Sci 37: 460-465, 2012.

21. Zhang JX, Song W, Chen ZH, Wei JH, Liao YJ, Lei J, Hu M, Chen GZ, Liao B, Lu J, Zhao HW, Chen W, He YL, Wang HY, Xie D and Luo JH: Prognostic and predictive value of a microRNA signature in stage II colon cancer: a microRNA expression analysis. Lancet Oncol 14: 1295-1306, 2013.

22. Frank GA, Danilova NV, Andreeva IuIu and Nefedova NA: WHO classification of tumors of the breast, 2012. Arkh Patol 75: 53-63, 2013 (In Russian).

23. Wang H, Peng W, Ouyang X, Li W and Dai Y: Circulating microRNAs as candidate biomarkers in patients with systemic lupus erythematosus. Transl Res 160: 198-206, 2012.

24. Tsui NB, Ng EK and Lo YM: Stability of endogenous and added RNA in blood specimens, serum, and plasma. Clin Chem 48: 1647-1653, 2002.

25. Mitchell PS, Parkin RK, Kroh EM, Fritz BR, Wyman SK, Pogosova-Agadjanyan EL, Peterson A, Noteboom J, O'Briant KC, Allen A, et al: Circulating microRNAs as stable blood based markers for cancer detection. Proc Natl Acad Sci USA 105: 10513-10518, 2008.

26. Wang H, Peng W, Ouyang X, Li W and Dai Y: miR-451 were upregulated in the patients with SLE and were also significantly increased in the patients with RA. J Transl Med 10: $55,2012$.

27. Kovalchuk O, Filkowski J, Meservy J, Ilnytskyy Y, Tryndyak VP, Chekhun VF and Pogribny IP: Involvement of microRNA-451 in resistance of the MCF-7 breast cancer cells to chemotherapeutic drug doxorubicin. Mol Cancer Ther 7: 2152-2159, 2008.

28. Li S, Yang C, Zhai L, Zhang W, Yu J, Gu F, Lang R, Fan Y, Gong M, Zhang X and Fu L: Deep sequencing reveals small RNA characterization of invasive micropapillary carcinomas of the breast. Breast Cancer Res Treat 136: 77-87, 2012.

29. Xu Q, Jiang Y, Yin Y, Li Q, He J, Jing Y, Qi YT, Xu Q, Li W, Lu B, Peiper SS, Jiang BH and Liu LZ. A regulatory circuit of miR-148a/152 and DNMT1 in modulating cell transformation and tumor angiogenesis through IGF-IR and IRS1. J Mol Cell Biol 5: 3-13, 2013

30. Tang W, Zhu J, Su S, Wu W, Liu Q, Su F and Yu F: MiR-27 as a prognostic marker for breast cancer progression and patient survival. PLoS One 7: e51702, 2012.

31. Catucci I, Verderio P, Pizzamiglio S, Bernard L, Dall'olio V, Sardella D, Ravagnani F, Galastri L, Barile M, Peissel B, et al: The SNP rs895819 in miR-27a is not associated with familial breast cancer risk in Italians. Breast Cancer Res Treat 133: 805-807, 2012.

32. Haque R, Chun E, Howell JC, Sengupta T, Chen D and Kim H: MicroRNA-30b-mediated regulation of catalase expression in human ARPE-19 cells. PLoS One 7: e42542, 2012. 
33. Ichikawa T, Sato F, Terasawa K, Tsuchiya S, Toi M, Tsujimoto G and Shimizu K: Trastuzumab produces therapeutic actions by upregulating miR-26a and miR-30b in breast cancer cells. PLoS One 7: e31422, 2012.

34. Van der Auwera I, Limame R, van Dam P, Vermeulen PB, Dirix LY and Van Laere SJ: Integrated miRNA and mRNA expression profiling of the inflammatory breast cancer subtype. Br J Cancer 103: 532-541, 2010.

35. Rouas R, Fayyad-Kazan H, El Zein N, Lewalle P, Rothé F, Simion A, Akl H, Mourtada M, El Rifai M, Burny A, et al: Human natural Treg microRNA signature: role of microRNA-31 and microRNA-21 in FOXP3 expression. Eur J Immunol 39: $1608-1618,2009$

36. Chang SJ, Weng SL, Hsieh JY, Wang TY, Chang MD and Wang HW: MicroRNA-34a modulates genes involved in cellular motility and oxidative phosphorylation in neural precursors derived from human umbilical cord mesenchymal stem cells. BMC Med Genomics 4: 65, 2011.

37. Ng EK, Li R, Shin VY, Jin HC, Leung CP, Ma ES, Pang R, Chua D, Chu KM, Law WL, Law SY, Poon RT and Kwong A: Circulating microRNAs as specific biomarkers for breast cancer detection. PLoS One 8: e53141, 2013.

38. Iguchi $\mathrm{H}$, Kosaka $\mathrm{N}$ and Ochiya T: Secretory microRNAs as a versatile communication tool. Commun Integr Biol 3: 478-481, 2010.

39. Kosaka N, Iguchi $\mathrm{H}$ and Ochiya T. Circulating microRNA in body fluid: a new potential biomarker for cancer diagnosis and prognosis. Cancer Sci 101: 2087-2092, 2010.
40. Catucci I, Verderio P, Pizzamiglio S, Bernard L, Dall'olio V, Sardella D, Ravagnani F, Galastri L, Barile M, Peissel B, Zaffaroni D, Manoukian S, Radice P and Peterlongo P: The SNP rs895819 in miR-27a is not associated with familial breast cancer risk in Italians. Breast Cancer Res Treat 133: 805-807, 2012.

41. Hezova R, Kovarikova A, Bienertova-Vasku J, Sachlova M, Redova M, Vasku A, Svoboda M, Radova L, Kiss I, Vyzula R and Slaby O: Evaluation of SNPs in miR-196-a2, miR-27a and miR-146a as risk factors of colorectal cancer. World J Gastroenterol 18: 2827-2831, 2012.

42. Katada T, Ishiguro H, Kuwabara Y, Kimura M, Mitui A, Mori Y, Ogawa R, Harata K and Fujii Y: microRNA expression profile in undifferentiated gastric cancer. Int J Oncol 34: 537-542, 2009.

43. Redova M, Poprach A, Nekvindova J, Iliev R, Radova L, Lakomy R, Svoboda M, Vyzula R and Slaby O: Circulating miR-378 and miR-451 in serum are potential biomarkers for renal cell carcinoma. J Transl Med 10: 55, 2012.

44. Zheng B, Liang L, Wang C, Huang S, Cao X, Zha R, Liu L, Jia D, Tian Q, Wu J, et al: MicroRNA-148a suppresses tumor cell invasion and metastasis by downregulating ROCK1 in gastric cancer. Clin Cancer Res 17: 7574-7583, 2011.

45. Wszolek MF, Rieger-Christ KM, Kenney PA, Gould JJ, Silva Neto B, Lavoie AK, Logvinenko T, Libertino JA and Summerhayes IC: A MicroRNA expression profile defining the invasive bladder tumor phenotype. Urol Oncol 29: 794-801, 2011

46. Gao W, Shen H, Liu L, Xu J, Xu J and Shu Y: MiR-21 overexpression in human primary squamous cell lung carcinoma is associated with poor patient prognosis. J Cancer Res Clin Oncol 137: 557-566, 2011. 